Open

\title{
Microbiota of De-Novo Pediatric IBD: Increased Faecalibacterium Prausnitzii and Reduced Bacterial Diversity in Crohn's But Not in Ulcerative Colitis
}

Richard Hansen, MBChB'1,2, Richard K. Russell, MBChB, PhD³, Caroline Reiff, PhD ${ }^{4}$, Petra Louis, PhD ${ }^{5}$, Freda Mclntosh, BSc 5 , Susan H. Berry¹, Indrani Mukhopadhya, PhD ${ }^{1}$, W. Michael Bisset, MBChB, MD' ${ }^{6}$ Andy R. Barclay, MBChB, MD³, Jon Bishop, MBChB ${ }^{3}$, Diana M. Flynn, MBChB, PhD³, Paraic McGrogan, MBChB³ , Sabarinathan Loganathan, MBChB ${ }^{6}$, Gamal Mahdi, MBChB ${ }^{6}$, Harry J. Flint, $\mathrm{PhD}^{5}$, Emad M. El-Omar, MBChB, MD and Georgina L. Hold, PhD ${ }^{1}$

OBJECTIVES: The gastrointestinal microbiota is considered important in inflammatory bowel disease (IBD) pathogenesis. Discoveries from established disease cohorts report reduced bacterial diversity, changes in bacterial composition, and a protective role for Faecalibacterium prausnitzii in Crohn's disease (CD). The majority of studies to date are however potentially confounded by the effect of treatment and a reliance on established rather than de-novo disease.

METHODS: $\quad$ Microbial changes at diagnosis were examined by biopsying the colonic mucosa of 37 children: 25 with newly presenting, untreated IBD with active colitis (13 CD and 12 ulcerative colitis (UC)), and 12 pediatric controls with a macroscopically and microscopically normal colon. We utilized a dual-methodology approach with pyrosequencing (threshold $>10,000$ reads) and confirmatory real-time PCR (RT-PCR).

RESULTS: $\quad$ Threshold pyrosequencing output was obtained on 34 subjects (11 CD, $11 \mathrm{UC}, 12$ controls). No significant changes were noted at phylum level among the Bacteroidetes, Firmicutes, or Proteobacteria. A significant reduction in bacterial $\alpha$-diversity was noted in CD vs. controls by three methods (Shannon, Simpson, and phylogenetic diversity) but not in UC vs. controls. An increase in Faecalibacterium was observed in CD compared with controls by pyrosequencing (mean $16.7 \%$ vs. $9.1 \%$ of reads, $P=0.02$ ) and replicated by specific $F$. prausnitzii RT-PCR $(36.0 \%$ vs. $19.0 \%$ of total bacteria, $P=0.02$ ). No disease-specific clustering was evident on principal components analysis.

CONCLUSIONS: Our results offer a comprehensive examination of the IBD mucosal microbiota at diagnosis, unaffected by therapeutic confounders or changes over time. Our results challenge the current model of a protective role for $F$. prausnitzii in $C D$, suggesting a more dynamic role for this organism than previously described.

SUPPLEMENTARY MATERIAL is linked to the online version of the paper at http://www. nature.com/ajg

Am J Gastroenterol 2012; 107:1913-1922; doi:10.1038/ajg.2012.335; published online 9 October 2012

\section{INTRODUCTION}

Inflammatory bowel disease (IBD) comprises a group of disorders characterized by chronic intestinal inflammation with the main phenotypes being Crohn's disease (CD) and ulcerative colitis (UC). The incidence of IBD is rising, especially in children (1-3). Genetic discoveries implicate intracellular bacterial recognition (NOD2) and mechanisms of intracellular bacterial handling such as autophagy $(4,5)$. The importance of the host innate immune response to bacteria highlighted by these discoveries has resulted in a renewed interest in the intestinal microbiota in IBD. The microbiota fulfills important roles in immunological development, defense against pathogens, 
production of exogenous enzymes, and salvage of dietary energy $(6,7)$. Studies on the microbiota of IBD have revealed changes in its composition, which are now part of the disease pathogenesis paradigm. These include an increase in bacterial numbers, a reduction in bacterial diversity, increases in the phyla Proteobacteria and Bacteroidetes, and a reduction in Firmicutes (8-11). The published evidence to date has relied on largely opportunistic studies of patients with established disease, providing a microbial snapshot of the chronic disease state at various time points after diagnosis. A significant limitation of this approach however is that the major confounders of active treatment and disease chronicity make it impossible to interpret events following on from disease initiation (12). The interrogation of the fecal microbiota in many studies also introduces a difficulty, as the mucosal and fecal bacterial ecosystems are recognized as being distinct in health, but with little known in disease states $(13,14)$.

Pediatric IBD offers an opportunity to explore these problems, since children are relatively free of additional significant comorbidities and are generally treatment naïve at IBD diagnosis. For these reasons, we set up the "Bacteria in Inflammatory bowel disease in Scottish Children Undergoing Investigation before Treatment" (BISCUIT) study.

\section{METHODS}

\section{Patient recruitment, biopsy collection, and processing}

Patients were recruited to the BISCUIT study from routine colonoscopy lists in each of three pediatric centers (Royal Aberdeen Children's Hospital, Aberdeen; Royal Hospital for Sick Children, Glasgow; and Ninewells Hospital, Dundee). An initial approach with study information was made either by post in advance of admission or on the day of admission, a minimum of $12 \mathrm{~h}$ in advance of the procedure. Patients under investigation in the pediatric centers were approached if the attending clinician deemed it possible that they would be found to have either IBD or a normal colon at colonoscopy. Patients were excluded if they had received systemic antibiotics or steroids in the 3 months before their colonoscopy or immunosuppression at any time, or if they had a previous diagnosis of IBD. All patients were investigated as per the Porto criteria, then diagnosed and phenotyped with reference to standard criteria (15-18).

Over 3 years the study recruited 100 children undergoing colonoscopy throughout Scotland in two categories, those with likely IBD, at first presentation, with macroscopic colonic inflammation $(n=45)$ and those undergoing colonoscopy who subsequently had a normal colon macroscopically $(n=55)$. The final IBD cohort comprised 44 confirmed IBD subjects (29 CD, 13 UC, and 2 IBD, type unclassified). The remaining "likely IBD" (inflamed colon) subject had mild, non-specific chronic inflammation in their distal colon on histopathology. This was insufficient to warrant a formal IBD diagnosis.

Biopsies were taken from a single site, from the distal colon in controls (rectum/sigmoid), or from the most distal inflamed site in IBD. In all, 2-3 biopsies were collected using standard endoscopic forceps. Biopsies were collected into a sterile $1.5 \mathrm{ml}$ Eppendorf container and placed immediately onto ice before transfer to $-80^{\circ} \mathrm{C}$ storage.
To explore bacterial diversity, 37 subjects were identified for further analysis (Table 1; Supplementary Table 1). Twelve UC were included, all with distal colonic inflammation. Thirteen CD patients were identified with granulomatous change in their biopsy set, firmly supportive of their diagnosis, and distal colonic inflammation in keeping with $\mathrm{CD}$ (and hence distal colonic biopsies) to match colonic site with the control and UC cohorts. Twelve controls were selected as most representative of "normal," having both a macroscopically and a microscopically normal colon, matched as closely as possible for age and sex to the IBD groups. None of the controls have gone on to develop IBD with a mean time since endoscopy of 23 months (minimum 7 months).

DNA extraction of mucosal biopsies was performed using the commercially available Qiagen QIAamp Mini kit (Qiagen, Crawley, UK) with minor modifications (19). A test PCR was performed as described previously with biopsy DNA utilizing primers universal for bacteria to confirm the suitability of the DNA for further analysis (20).

Ethical approval was granted by North of Scotland Research Ethics Service (09/S0802/24) on behalf of all participating centers and written informed consent was obtained from the parents of all subjects. Informed assent was also obtained from older children who were deemed capable of understanding the nature of the study.

This study is publicly registered on the United Kingdom Clinical Research Network Portfolio (9633).

\section{Preparation of samples for pyrosequencing}

Biopsy DNA was quantified by Nanodrop mass spectrophotometry before dilution to $25 \mathrm{ng} / \mu \mathrm{l}$. Initial PCR amplification was undertaken with FastStart High Fidelity PCR reagents (Roche, Penzberg, Germany) utilizing a per-reaction mix of 50 ng of DNA template, $10 \times$ FastStart High Fidelity Reaction Buffer with $90 \mathrm{nM} \mathrm{MgCl}$, $10 \mathrm{nM}$ dNTPs, $10 \mathrm{pM}$ Fusion Primer A, $10 \mathrm{pM}$ Fusion Primer B, $5 \mathrm{U}$ FastStart High Fidelity Enzyme Blend. The $16 \mathrm{~S}$ rDNA primers were taken from Dethlefsen et al. (21); however, we utilized the $338 \mathrm{f}$ partnered with $1064 \mathrm{r}$, spanning the V3-V6 region of the $16 \mathrm{~S}$ rRNA gene and providing a $\sim 726$-bp product. For the forward primer, two multiplex identifiers (MID1 and MID2) were used to allow multiplexing of paired samples during sequencing. No identifier was added to the reverse primer. Hence, the $~ 726-$ bp PCR product was flanked by a 40-bp fusion primer/multiplex identifier sequence at the forward end and a 30-bp fusion primer at the reverse end therefore resulting in a $\sim 796-b p$ sequence. The final primers were A-338f1 5'-CCATCTCATCCCTGCGTGTCTCCGACTC AGACGAGTGCGTACTCCTACGGGAGGCAGCAG-3'; A-338f2 5'-CCATCTCATCCCTGCGTGTCTCCGACTCAGACGCTCG ACAACTCCTACGGGAGGCAGCAG-3' and B-1064r 5'-CCTAT CCCCTGTGTGCCTTGGCAGTCTCAGCGACARCCATG CASCACCT-3' (page-purified primers by Sigma-Aldrich, Gillingham, UK) with the bold sections corresponding to fusion primers, the underlined sections multiplex identifiers, and the standard text to the $16 \mathrm{~S}$ primers.

PCR cycling conditions were taken from the modified conditions of Dethlefsen and were briefly as follows: $3 \mathrm{~min}$ at $94^{\circ} \mathrm{C} ; 30$ cycles of $30 \mathrm{~s}$ at $94^{\circ} \mathrm{C}, 45 \mathrm{~s}$ at $55^{\circ} \mathrm{C}, 60 \mathrm{~s}$ at $72^{\circ} \mathrm{C} ; 2 \mathrm{~min}$ at $72^{\circ} \mathrm{C}(21)$. After confirmation of successful PCR amplification, products were 
Table 1. Statistical comparisons of study group demographics of original and final cohort

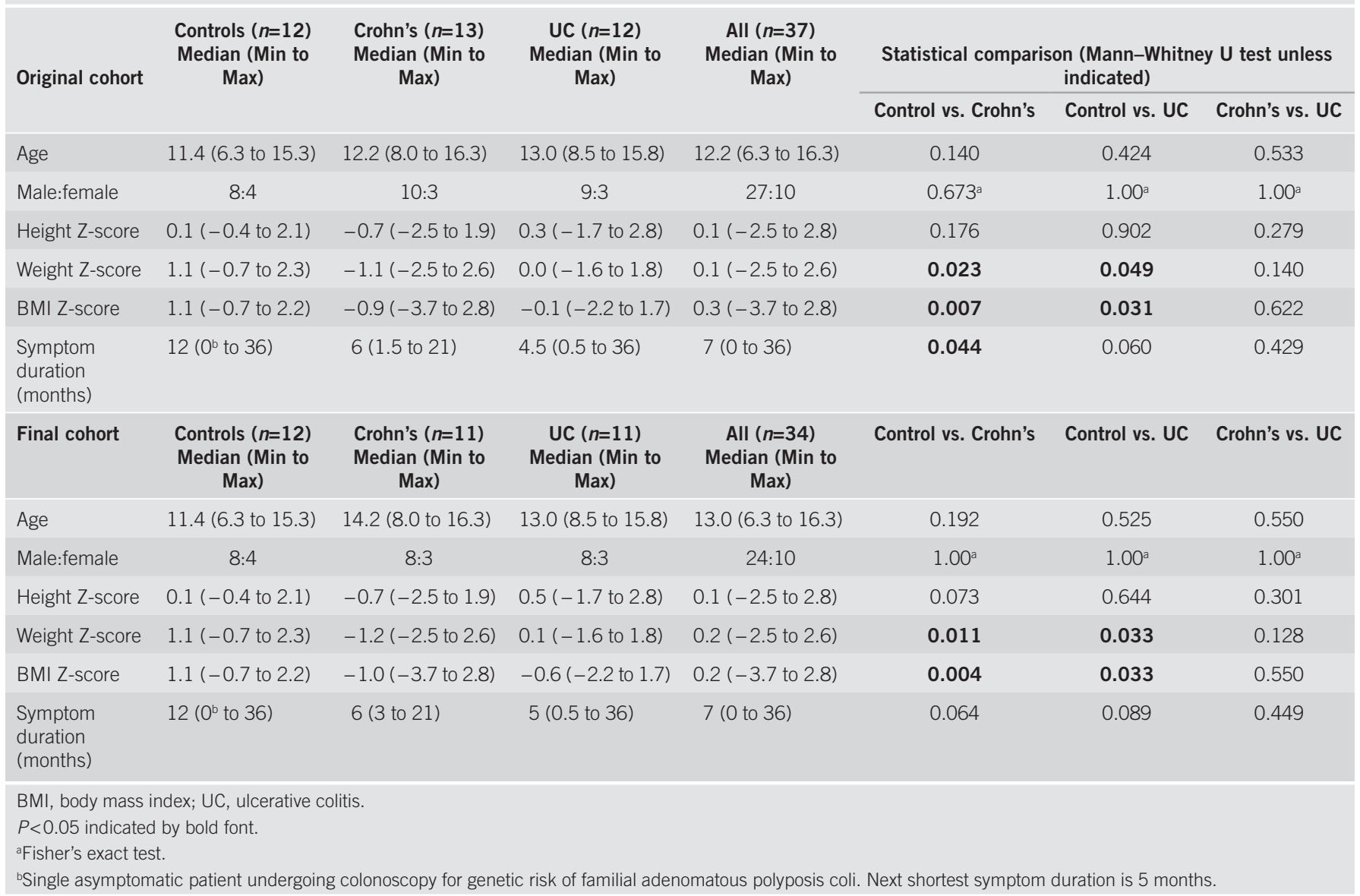

purified as per the recommended Agencourt AMPure (Beckman Coulter, Beverly, MA) purification method for 454 sequencing and sequenced on Roche 454 Titanium (454 Life Sciences, Branford, CT) by NewGene (Newcastle, UK).

\section{Real-time PCR}

Quantitative real-time PCR (RT-PCR) was performed as described previously (22). Briefly, standard curves consisted of 10-fold dilution series of amplified bacterial 16S rRNA genes from reference strains. Samples were amplified with universal primers against total bacteria and specific primers against Bacteroidetes, Firmicutes clostridial cluster IV, Firmicutes clostridial cluster XIVa, Enterobacteriaceae and Faecalibacterium prausnitzii (Table 2).

\section{Supplementary methods}

Supplementary Methods contain additional detail on RT-PCR methodology, bioinformatic analysis of pyrosequencing data, and statistical analyses.

\section{RESULTS}

Pyrosequencing generated $>1$ million individual sequencing reads in total with a mean yield of 21,691 reads per subject after bioinformatic processing but before rarefaction (Supplementary Table 2). Of the 37 subjects in the study, 2 did not meet the 10,000 read threshold and were excluded, 1 UC whose bacterial DNA amplified poorly and failed quality control for pyrosequencing and $1 \mathrm{CD}$ who was sequenced as all other subjects, but who only yielded 739 reads. In all, 1 further subject (CD) was sequenced and rarefied alongside the final 34, but $99.9 \%$ of their 11,000 reads were unmatched at phylum level. Thus, 34 subjects were ultimately represented by 11,000 rarefied reads after bioinformatic processing, allowing subjectto-subject comparison. The only resultant demographic change was a loss of significance in symptom duration between CD and controls (Table 1).

In all, 1 UC subject amplified poorly by RT-PCR despite successful pyrosequencing of their sample yielding 24,240 reads. A further attempt at RT-PCR with $50 \mathrm{ng}$ DNA template was also unsuccessful; therefore, this subject was not included in RT-PCR correlations $(n=33)$ but was included in pyrosequencing analyses $(n=34)$. Pyrosequencing findings correlated with RT-PCR results to a 0.01 significance level (Pearson coefficients: Bacteroidetes $0.624(n=33)$, Firmicutes $0.571 \quad(n=33)$, Proteobacteria 0.891 ( $n=20$, restricted to those where Proteobacteria were above RT-PCR detection threshold)). 
Bacterial diversity was significantly reduced in CD when compared with controls by three distinct indices (Shannon, Simpson, and Phylogenetic Diversity). No significant difference in bacterial diversity was noted between UC and controls by any of the five indices tested (Table 3).

Phylum-level diversity comparisons revealed no statistically significant differences for the three prevalent bacterial phyla of Bacteroidetes, Firmicutes, and Proteobacteria $(P=0.142-0.850$, ANOVA; Figure 1a-c; Table 4) and a significant result only in the numerically small phylum Actinobacteria between $\mathrm{CD}$ and controls (Table 4). Individual subject phylum-level diversity

Table 2. Real-time PCR primers used in this study

\begin{tabular}{|c|c|c|c|}
\hline Target group & Primer name & Primer sequence & Reference \\
\hline \multirow[t]{2}{*}{ All bacteria } & UniF & $\begin{array}{l}\text { GTGSTGCAYGGY } \\
\text { YGTCGTCA }\end{array}$ & $\begin{array}{l}\text { Ramirez-Farias } \\
\text { et al. (22) }\end{array}$ \\
\hline & UniR & $\begin{array}{l}\text { ACGTCRTCCMCN } \\
\text { CCTTCCTC }\end{array}$ & \\
\hline \multirow[t]{2}{*}{ Bacteroidetes } & Вас303F & $\begin{array}{l}\text { GAAGGTCCCCC } \\
\text { ACATTG }\end{array}$ & \\
\hline & Bfr-Fmrev & $\begin{array}{l}\text { CGCKACTTGGC } \\
\text { TGGTTCAG }\end{array}$ & \\
\hline \multirow[t]{2}{*}{$\begin{array}{l}\text { Clostridial } \\
\text { cluster XIVa }\end{array}$} & Erec482F & $\begin{array}{l}\text { CGGTACCTGA } \\
\text { CTAAGAAGC }\end{array}$ & \\
\hline & Erec870R & $\begin{array}{l}\text { AGTTTYATTCT } \\
\text { TGCGAACG }\end{array}$ & \\
\hline \multirow[t]{2}{*}{$\begin{array}{l}\text { Clostridial } \\
\text { cluster IV }\end{array}$} & Clep866mF & $\begin{array}{l}\text { TTAACACAATAAG } \\
\text { TWATCCACCTGG }\end{array}$ & \\
\hline & Clept1240mR & $\begin{array}{l}\text { ACCTTCCTCCG } \\
\text { TTTTGTCAAC }\end{array}$ & \\
\hline \multirow[t]{2}{*}{$\begin{array}{l}\text { Faecalibacteri- } \\
\text { um prausnitzii }\end{array}$} & FPR-2F & $\begin{array}{l}\text { GGAGGAAGAA } \\
\text { GGTCTTCGG }\end{array}$ & \\
\hline & Fprau645R & $\begin{array}{l}\text { AATTCCGCCTA } \\
\text { СCTCTGCACT }\end{array}$ & $\downarrow$ \\
\hline \multirow[t]{2}{*}{$\begin{array}{l}\text { Enterobacte- } \\
\text { riaceae }^{a}\end{array}$} & $\begin{array}{l}\text { Enterobact } \\
\text { Dmod2F }\end{array}$ & $\begin{array}{l}\text { GACCTCGCG } \\
\text { AGAGCA }\end{array}$ & $\begin{array}{l}\text { Walker et al. (47), } \\
\text { modified }\end{array}$ \\
\hline & Enter1432mod & $\begin{array}{l}\text { ССТАСТTCTTT } \\
\text { TGCAACCCA }\end{array}$ & $\begin{array}{l}\text { Sghir et al. (48), } \\
\text { modified }\end{array}$ \\
\hline
\end{tabular}

${ }^{a}$ Amplification conditions as described in Ramirez-Farias et al. (22), with primer annealing temperature of $63^{\circ} \mathrm{C}$ and extension at $72^{\circ} \mathrm{C}$ for $30 \mathrm{~s}$. showed some variability, particularly within Proteobacteria in UC (Figure 1d). Interestingly, a greater proportion of IBD reads were unmatched at phylum level, although these did not reach significance.DiversitycomparisonsbyRT-PCRalsorevealednostatistically significant differences for Bacteroidetes, Clostridial Cluster XIVa or Enterobacteriaceae ( $P=0.215-0.619$, ANOVA; Table 4), but did demonstrate a significant increase in Clostridial Cluster IV in CD vs. controls $(P=0.029)$.

An additional ANOVA comparison was made between each of the three pairings (CD vs. Controls, UC vs. controls, and CD vs. UC) against the top $99.9 \%$ of genus-level matches (78 genera). Of a possible 234 comparisons, only 7 achieved statistical significance. These were Faecalibacterium, $\mathrm{CD}>\mathrm{Controls}$ (mean 1,841.1 $( \pm 1,004.6)$ vs. $921.7( \pm 794.8)$ reads, $P=0.023)$; Parabacteroides, Control $>$ UC (mean $406.0( \pm 427.9)$ vs. 113.6 $( \pm 87.8)$ reads, $P=0.038$ ); Roseburia, UC $>\mathrm{CD}$ (mean 159.2 $( \pm 171.2)$ vs. $37.0( \pm 30.0)$ reads, $P=0.030)$; Burkholderiales (/Other/Other), Control $>$ UC (mean $53.3( \pm 58.2)$ vs. $5.1( \pm 8.1)$ reads, $P=0.013$ ); Prevotellaceae (/Other), $\mathrm{UC}>\mathrm{CD}$ (mean 21.8 $( \pm 25.5)$ vs. $2.7( \pm 3.7)$ reads, $P=0.023)$; Desulfovibrio, $\mathrm{UC}>\mathrm{CD}$ (mean $21.5( \pm 25.3)$ vs. $2.7( \pm 3.1), P=0.024)$; and Coriobacteriaceae, Control $>\mathrm{CD}$ (mean $15.7( \pm 16.9)$ vs. $2.7( \pm 2.9)$, $P=0.021)$.

The Faecalibacterium finding (1,841.1 reads ( $16.7 \%$ of all reads) from $\mathrm{CD}$ vs. $1,004.6$ reads ( $8.4 \%$ of all reads) from controls, $P=0.02$ ) was replicated with $F$. prausnitzii-specific RT-PCR (correlated with a 0.01 significance level with pyrosequencing data with a Pearson coefficient of $0.894, n=33$ ), which revealed mean prevalence of $36.0( \pm 18.1) \%$ of all bacteria in CD vs. $19.0( \pm 14.1) \%$ in controls $(P=0.02)$. Prevalence in UC was similar to controls by both methods (pyrosequencing from ANOVA: $10.1( \pm 11.9) \%$ of UC reads vs. $8.4( \pm 7.2) \%$ of controls, $F=0.187, P=0.7$; RT-PCR by $t$-test: $25.5( \pm 26.7) \%$ of UC reads vs. $19.0( \pm 14.1) \%$ of controls, $P=0.5$ ) (Figure 2). The difference between CD and UC did not reach statistical significance by either method (pyrosequencing $P=0.16$, RT-PCR $P=0.3$ ).

To explore clustering within disease categories, principal components analysis (PCA) was undertaken on weighted Unifrac distances (Figure 3). Interestingly, no distinct group clustering was observed within any phenotypic group. Although microbial diversity was significantly reduced in $\mathrm{CD}$, this was not reflected by distinct clustering of $\mathrm{CD}$ subjects on PCA.

Table 3. Indices of bacterial $\alpha$-diversity from pyrosequencing data

\begin{tabular}{|c|c|c|c|c|c|c|}
\hline \multirow[b]{3}{*}{ Shannon } & \multirow[t]{2}{*}{ Control } & Crohn's & UC & \multicolumn{3}{|c|}{ Statistical comparison by $t$-test } \\
\hline & & \multicolumn{2}{|c|}{ Mean ( \pm standard deviation) } & Control vs. Crohn's & Control vs. UC & Crohn's vs. UC \\
\hline & $5.59( \pm 0.30)$ & $5.15( \pm 0.46)$ & $5.54( \pm 0.64)$ & 0.017 & 0.835 & 0.119 \\
\hline Simpson & $0.96( \pm 0.01)$ & $0.93( \pm 0.04)$ & $0.94( \pm 0.04)$ & 0.042 & 0.227 & 0.429 \\
\hline Chao 1 & $448.6( \pm 103.2)$ & $428.0( \pm 194.4)$ & $552.0( \pm 286.5)$ & 0.758 & 0.279 & 0.251 \\
\hline Observed species & $273.9( \pm 42.7)$ & $275.7( \pm 79.7)$ & $317.3( \pm 124.6)$ & 0.947 & 0.294 & 0.365 \\
\hline
\end{tabular}




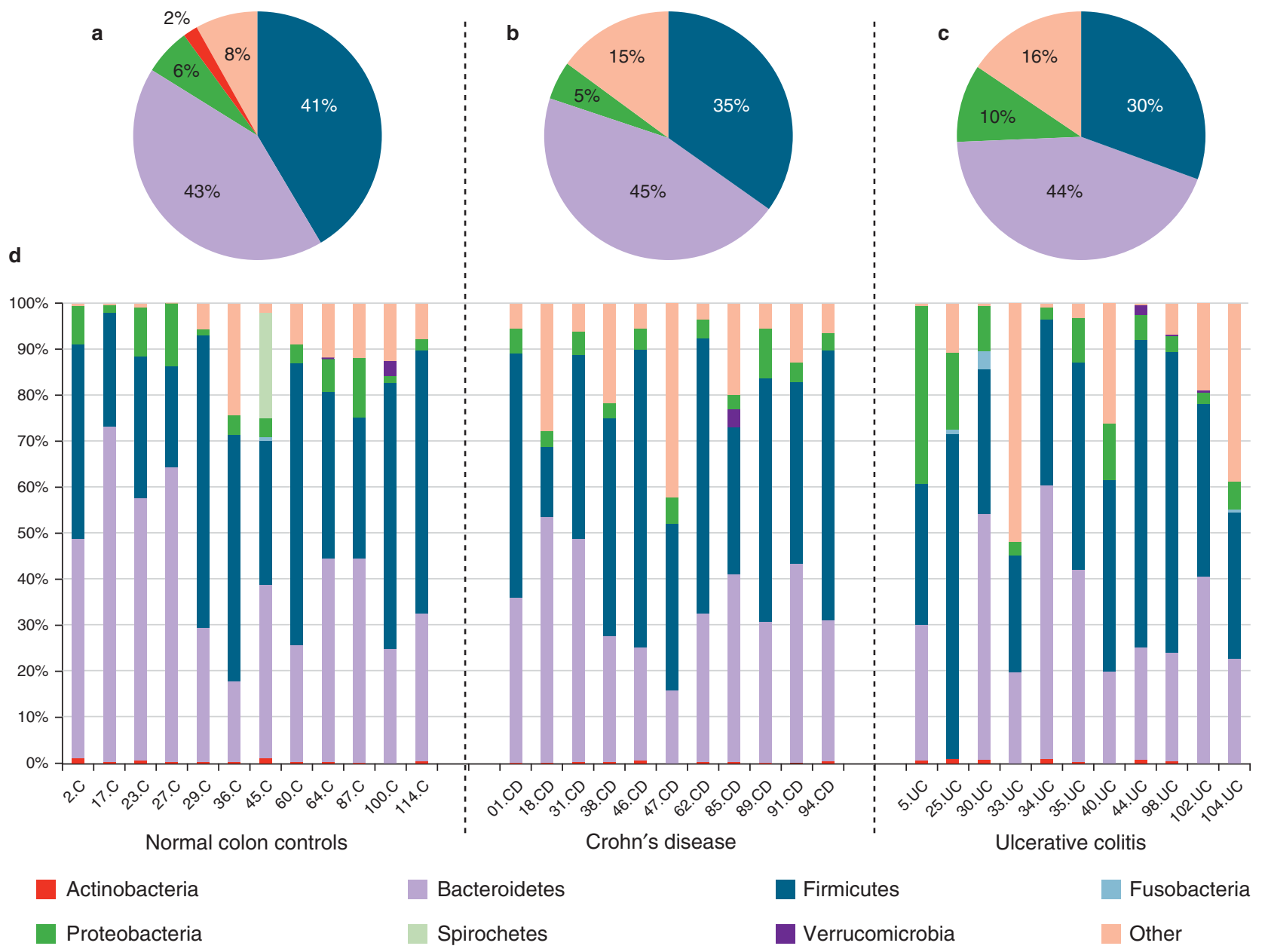

Figure 1. Phylum-level diversity assessment. (a-c) Pie charts comprised all patient rarefied reads (11,000 reads per patient) to represent overall diversity of each cohort; phyla comprising < $1 \%$ have been removed for clarity. (a) Normal colon controls comprising 12 patients. (b) Crohn's disease comprising 11 patients. (c) Ulcerative colitis (UC) comprising 11 patients. (d) Individual patient diversity at phylum level as stacked bars. Individual patient data are presented in Supplementary Table 1. Spirochetes were identified in a single Control patient (BISCUIT number 45) and were not noted on histopathology. No Bacteroidetes were identified in a single UC patient (BISCUIT number 25). BISCUIT, Bacteria in Inflammatory bowel disease in Scottish Children Undergoing Investigation before Treatment.

\section{DISCUSSION}

Our data describe a previously unexplored epoch in IBD microbiology, namely the onset of disease in treatment naive children. A single adult study at IBD onset noted a significant difference in unclassified Bacteroidetes between CD and both UC and control patients, but no other significant phylum changes when intestinal biopsies were examined by denaturing gradient gel electrophoresis and clone libraries (23). Our study remains unique in the IBD literature by addressing the mucosal microbiota at the onset of disease in a population of treatment naïve children utilizing a deep sequencing approach, corroborated by RT-PCR. Our data challenge the view that phylum-level changes are important in IBD etiology, cast doubt on the notion that a reduction in bacterial diversity occurs in UC, but firmly support this same hypothesis in $\mathrm{CD}$, thus demonstrating an important microbial distinction between these two conditions. Our bacterial diversity results probably indicate a true reduction associated with $\mathrm{CD}$, as both the $\mathrm{CD}$ and UC samples were obtained from inflamed tissue; hence, the reduction is not simply an artifact of inflammation. Interestingly, a similar reduction in bacterial diversity has recently been noted in the oral microbiota of children with $\mathrm{CD}$, but not in those with UC or healthy children (24). Adult studies examining biopsies from both active and quiescent UC suggest a reduction in bacterial diversity in the former $(25,26)$. Our UC cohort have active inflammation and are untreated, suggesting that the causative agent of a reduction in bacterial diversity is perhaps more complex than simply the presence of inflammation.

PCA, a useful method of comparing diversity between individuals and looking for disease-specific microbial clustering, showed no clear distinctions between each of the three phenotypes we have studied (controls, CD, and UC). The landmark paper by Frank et al. (27) utilizing PCA in adult IBD biopsies outlined nominal sample clusters between an IBD subset and a control subset, nevertheless the phenotypic distinction on PCA was not absolute. Others 
Table 4. Phylum-level statistical comparisons for pyrosequencing data against equivalent RT-PCR

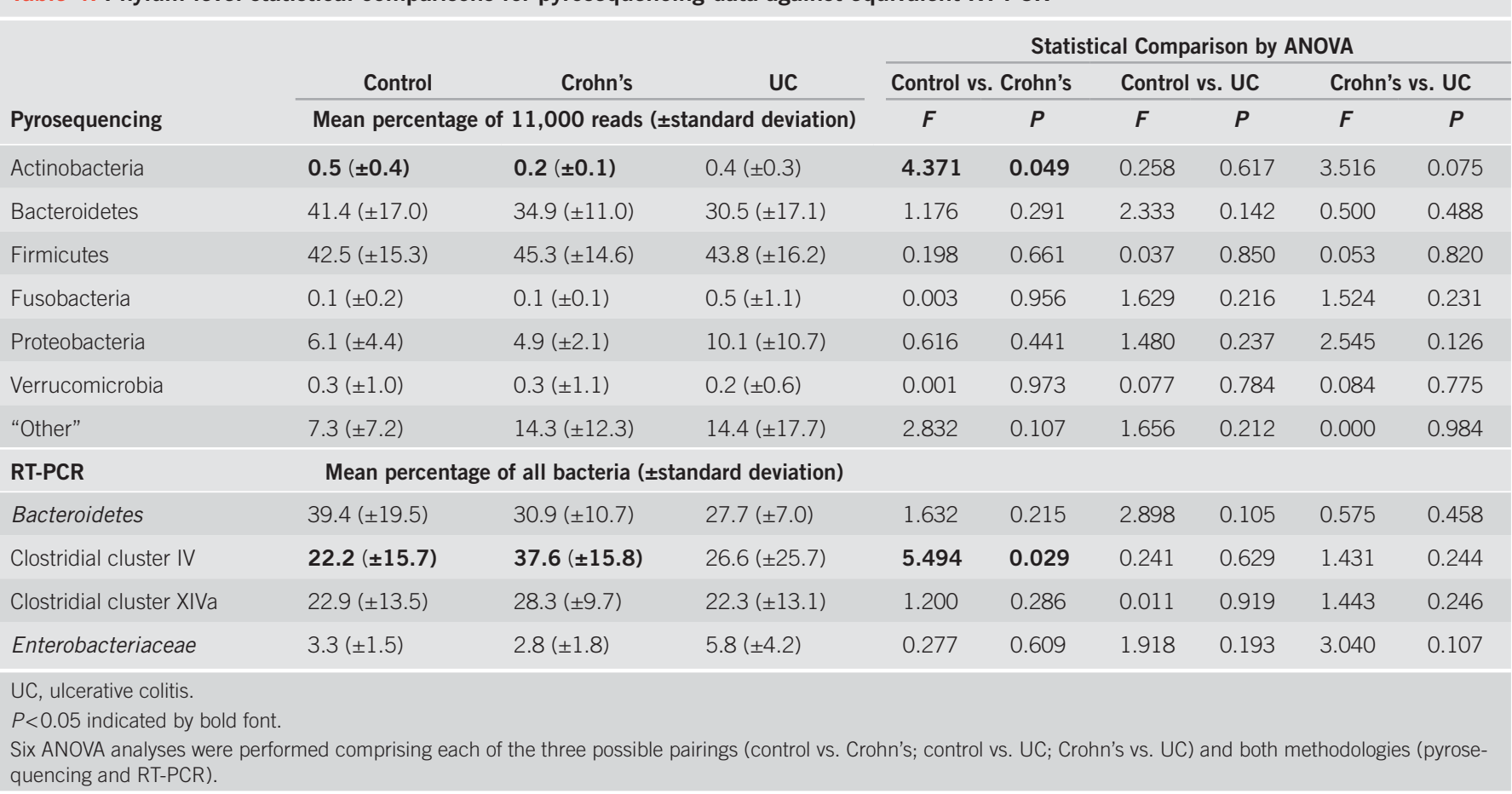

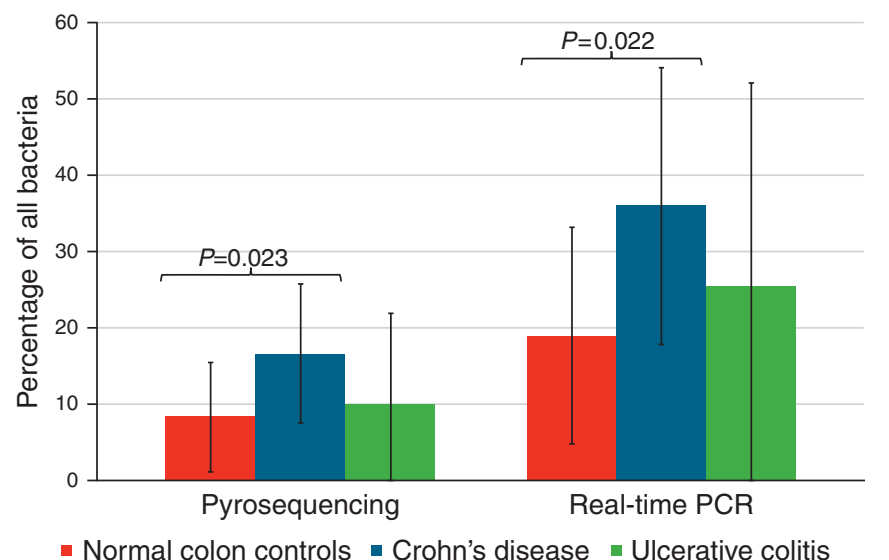

Figure 2. Comparison of mean prevalence ( \pm standard deviation) of Faecalibacterium genus by pyrosequencing and Faecalibacterium prausnitzii by real-time PCR against all bacteria in the distal colon of children with a normal colon, Crohn's disease, and ulcerative colitis.

such as Walker et al. (28) have shown clear distinctions between disease phenotype using similar methods. The lack of differentiation we have shown suggests evolution as disease enters chronicity, or perhaps that such differentiation is merely an artifact of disease-specific treatment strategies.

We propose that the current literature on IBD microbiology more accurately reflects changes associated with disease chronicity, and as such should not be extrapolated to the onset of disease. Furthermore, the important issue of active treatment, which is problematic when studying established disease, adds an important confounder which is underemphasized in the published literature.

In our study, all subjects received stimulant bowel preparation before colonoscopy. This may have altered the microbial profile of the colonic mucosa, however since the treatment was given to all, this would likely act equivalently between groups. Furthermore, the organisms least likely to be affected would be those with adherent properties, of most interest in the mucosal disease of IBD. In support of our approach, other investigators have demonstrated differences in the IBD microbiota despite prior bowel preparation $(10,29)$. Finally, a study design where children undergo diagnostic colonoscopy under general anesthetic without adequate preparation would be ethically unacceptable. Related to this latter point, the controls in this study were children undergoing colonoscopy to investigate gastrointestinal symptoms. They were not therefore strictly "healthy" controls; however, we have tried to address this by selecting only those with a macroscopically and microscopically normal colon for inclusion.

Although genetically similar (30), there are important distinctions between adult and pediatric IBD with the latter being characterized by a more extensive phenotype (31) and, at least in the case of CD, by a distinct immunophenotype (32). Environmental factors such as gastrointestinal microbial colonization may be etiological factors of relevance to this distinction; hence, it is entirely possible that pediatric IBD is defined by a unique microbial signature, distinct from the adult disease.

Irrespective of the lack of phylum-level changes seen in our results at diagnosis, it appears that fecal microbial changes can be used as a useful biomarker for disease progression in children with 


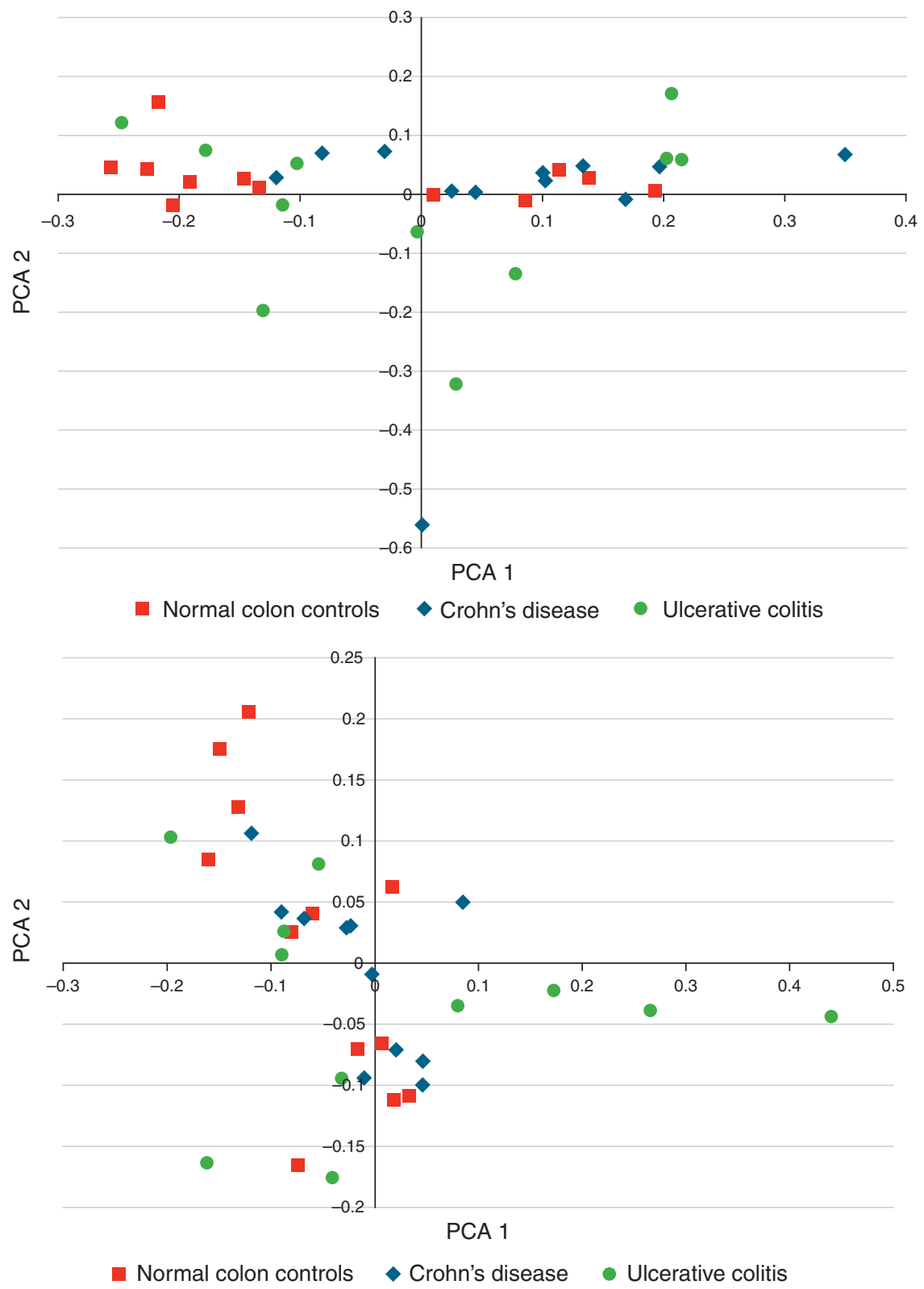

Figure 3. Principal components analysis (PCA) of weighted Unifrac distances for denoised, chimera-checked pyrosequencing data with $97 \%$ (top) and 95\% (bottom) OTU clustering demonstrating PCA 1 vs. PCA 2 for normal colon controls, Crohn's disease, and ulcerative colitis. No distinct clustering is seen within phenotypic groups.

UC (33). The study of Michail et al. (33) demonstrated alterations in the fecal microbiota of pediatric UC vs. healthy controls, but also showed that UC non-responders to steroid treatment demonstrated fewer phylotypes within their fecal samples compared with responders when examined by microarray. This study raises an interesting consideration regarding microbial findings in IBD, since the alterations seen could reflect either causation or proxy association; nevertheless, their clinical utility as a biomarker may be sufficient alone to warrant their further exploration. Our own UC results were surprisingly similar to our normal colon control group, suggesting that the UC-specific fecal alterations described by Michail et al. may reflect an influence on the fecal stream rather than on gastrointestinal colonization per se. Two explanations might be increased gastrointestinal transit (diarrhea) and anorexia in active UC. Understanding the impact of such influences and separating them from true etiological factors is a significant challenge in gastrointestinal community microbiology.

Perhaps of most interest, we demonstrated a significant increase in F. prausnitzii in CD at diagnosis, in marked contrast with previous reports of a reduction in the species in adult $\operatorname{CD}(29,34,35)$.

F. prausnitzii is likely to have an important role in CD; however, its role may be more complex than our current understanding. It is clear from the seminal study of Sokol et al. (34) that this single species is positively associated with an improved 
outcome in established adult $\mathrm{CD}$, with the demonstration that reduction in the proportion of this bacterium in intestinal samples was associated with endoscopic recurrence of disease. The same paper demonstrated the anti-inflammatory properties of the bacterium in both a human in vitro cell model and a murine in vivo colitis model (34). The inference of course is that the reduction of $F$. prausnitzii in CD is not simply a proxy for worsening inflammation/disease, but that the organism is an integral component of the anti-inflammatory balance in health and its reduction may directly contribute to promotion of the disease state. Our data directly contradict this hypothesis. One possible explanation might be highlighted by Bacteroides fragilis, an organism found to be capable of initiating colitis in animal models (36), but also of directing an anti-inflammatory immune response $(37,38)$. Individual components of the microbiota may thus fulfill differing roles under different conditions. Whether the increase in F. prausnitzii seen in CD within our study represents a hitherto undescribed pro-inflammatory role for the species, whether the early host/microbiota response to IBD induces proliferation of F. prausnitzii in an attempt to reverse the inflammatory change or whether the changes seen here are a proxy for some other phenomenon remains to be explained.

A single study from Jia et al. (39) reported a correlation between clinical improvement and a reduction in fecal F. prausnitzii abundance in patients with $\mathrm{CD}$ who responded to enteral nutrition therapy. The authors explained their surprising F. prausnitzii observation by commenting that it may merely be an innocent bystander in CD. Our data using more robust methodology are the first to demonstrate an increase in this bacterium at $\mathrm{CD}$ diagnosis, which suggests a more complex and integral role for $F$. prausnitzii in CD pathogenesis. Interestingly, the data of Willing et al. (29), derived from pyrosequencing of fecal samples in established disease, demonstrated an increase in Faecalibacterium in colonic, but a reduction in ileal $\mathrm{CD}$ although the former was not elaborated fully on within the paper.

Enteral nutrition is widely used in the management of pediatric $\mathrm{CD}$, achieving high rates of remission in all phenotypes (40). Its mode of action remains to be explained fully, although published studies to date suggest that changes in the microbiota parallel clinical response (41). A recent study demonstrated a reduction in fecal F. prausnitzii in healthy adults fed a low fiber enteral feed (42). Considering this paper in tandem with our results, one could hypothesize that enteral nutrition results in a temporary reduction of bacterial load, especially F. prausnitzii whose growth is known to be stimulated by acetate produced by other bacteria, as well as by substrates supplied from a normal balanced diet. This could in turn lead to a temporary remission from $\mathrm{CD}$ activity. This hypothesis would fit with the transient nature of enteral nutrition-induced remission in pediatric $\mathrm{CD}$, with $60-70 \%$ of patients relapsing within 12 months of cessation (43).

Another possible mechanism is suggested by very recent evidence that $F$. prausnitzii, although hitherto regarded as a strict anaerobe, has the ability to use low concentrations of oxygen as an electron acceptor through extracellular electron transfer (44). It is proposed that this ability may equip $F$. prausnitzii for survival at the interface between oxygenated and anaerobic zones close to the colonic wall, which appears consistent with the high representation of $F$. prausnitzii noted here in biopsy samples. Disturbance to the colonic mucosa and mucus layer in disease states is likely to affect local oxygen gradients, with consequences for F. prausnitzii populations.

Our study has generated novel and intriguing data especially with regard to $F$. prausnitzii however larger prospective followup studies, with serial sampling of the mucosal microbiota at diagnosis and at opportunistic times throughout treatment, would further improve our understanding of the microbiology of these chronic diseases. Such studies would lend important insight into longitudinal microbial changes and their relationship with the potential confounders outlined above, hopefully helping to explain the complexities of the IBD microbiota and important organisms such as $F$. prausnitzii, with direct implications for disease treatment. The recent publication of data from the Human Microbiome Project has clearly shown the abundance, diversity and physiological importance of our microbial cohabitants and provided scaffolding for future studies $(45,46)$. A greater understanding of the microbial pathogenesis of IBD is now within our grasp.

\section{ACKNOWLEDGMENTS}

We are grateful for the expertise of our sequencing provider NewGene and in particular for the support and help of Dr Jonathan Coxhead. Mrs Karen McIntyre and Dr Dagmar Kastner were invaluable in identifying patients for recruitment in Dundee. Mrs Ann Morrice provided administrative support in Aberdeen. Dr Paul Henderson gave helpful comments on the manuscript. We appreciate the generosity of the families who freely gave their time and samples to make this study possible and the theatre staff of all centers who allowed time for sample collection during busy endoscopy lists.

\section{CONFLICT OF INTEREST}

Guarantor of the article: Georgina L. Hold, PhD.

Specific author contributions: Designed the study: Richard Hansen, Emad M. El-Omar, Georgina L. Hold, Caroline Reiff, and Richard K. Russell; study coordinator: Richard Hansen; identified and recruited patients for the study: Richard Hansen, Richard K. Russell, W. Michael Bisset, Andy R. Barclay, Jon Bishop, Diana M. Flynn, Paraic McGrogan, Sabarinathan Loganathan and Gamal Mahdi; undertook the experiments: Richard Hansen, Petra Louis, Freda McIntosh, Susan H. Berry, Indrani Mukhopadhya, and Georgina L. Hold; performed bioinformatic analysis of the sequencing data: Caroline Reiff; performed statistical analyses: Richard Hansen; wrote the manuscript: Richard Hansen, Georgina L. Hold, Caroline Reiff, Petra Louis, Richard K. Russell, and Emad M. El-Omar; all authors reviewed it and agreed on the final version.

Financial support: This work was funded by a Clinical Academic Training Fellowship from the Chief Scientist Office in Scotland (CAF/08/01) which also funded the salary of RH and a project grant from Crohn's in Childhood Research Association (CICRA). The Royal Hospital for Sick Children, Glasgow IBD team is generously supported by the Catherine McEwan Foundation and the Yorkhill IBD fund. RKR is supported by an NHS Research Scotland 
career fellowship award. The funders had no role in study design, data collection and analysis, decision to publish, or preparation of the manuscript.

Potential competing interests: None.

\section{Study Highlights}

\section{WHAT IS CURRENT KNOWLEDGE}

The intestinal microbiota is considered as pivotal in inflammatory bowel disease (IBD) pathogenesis.

Established adult IBD is associated with microbial changes and a reduction in bacterial diversity.

Faecalibacterium prausnitzii appears to have a protective role in established adult Crohn's disease.

\section{WHAT IS NEW HERE}

Phylum-level bacterial changes are not important in pediatric inflammatory bowel disease (IBD) at diagnosis.

Bacterial diversity is reduced in de-novo pediatric Crohn's disease but not in ulcerative colitis.

Faecalibacterium prausnitzii is increased in the colonic mucosa of newly diagnosed Crohn's disease, suggesting a more complex role for the organism.

\section{REFERENCES}

1. Benchimol EI, Fortinsky KJ, Gozdyra P et al. Epidemiology of pediatric inflammatory bowel disease: a systematic review of international trends. Inflamm Bowel Dis 2011;17:423-39.

2. Molodecky NA, Soon IS, Rabi DM et al. Increasing incidence and prevalence of the inflammatory bowel diseases with time, based on systematic review. Gastroenterology 2012;142:46-54.

3. Henderson P, Hansen R, Cameron FL et al. Rising incidence of pediatric inflammatory bowel disease in Scotland. Inflamm Bowel Dis 2012;18: 999-1005.

4. Travassos LH, Carneiro LAM, Ramjeet M et al. Nod1 and Nod2 direct autophagy by recruiting ATG16L1 to the plasma membrane at the site of bacterial entry. Nat Immunol 2009;11:55-62.

5. Cooney R, Baker J, Brain O et al. NOD2 stimulation induces autophagy in dendritic cells influencing bacterial handling and antigen presentation. Nat Med 2009;16:90-7.

6. Guarner F, Malagelada JR. Gut flora in health and disease. Lancet 2003;361:512-9.

7. Round JL, Mazmanian SK. The gut microbiota shapes intestinal immune responses during health and disease. Nat Rev Immunol 2009;9:313-23.

8. Swidsinski A, Ladhoff A, Pernthaler A et al. Mucosal flora in inflammatory bowel disease. Gastroenterology 2002;122:44-54.

9. Ott SJ, Musfeldt M, Wenderoth DF et al. Reduction in diversity of the colonic mucosa associated bacterial microflora in patients with active inflammatory bowel disease. Gut 2004;53:685-93.

10. Conte MP, Schippa S, Zamboni I et al. Gut-associated bacterial microbiota in paediatric patients with inflammatory bowel disease. Gut 2006;55:1760-7.

11. Sokol H, Lay C, Seksik P, Tannock GW. Analysis of bacterial bowel communities of IBD patients: What has it revealed? Inflamm Bowel Dis 2008;14:858-67.

12. Mukhopadhya I, Hansen R, El-Omar EM, Hold GL. IBD- what role do proteobacteria play? Nat Rev Gastroenterol Hepatol 2012;9:219-30.

13. Eckburg PB, Bik EM, Bernstein CN et al. Diversity of the human intestinal microbial flora. Science 2005;308:1635-8.

14. Momozawa Y, Deffontaine V, Louis E, Medrano JF. Characterization of bacteria in biopsies of colon and stools by high throughput sequencing of the V2 region of bacterial 16S rRNA gene in human. PLoS ONE 2011;6:e16952.

15. Lennard-Jones JE. Classification of inflammatory bowel disease. Scand J Gastroenterol 1989;24:2-6.

16. IBD Working Group of the European Society for Paediatric Gastroenterology, Hepatology and Nutrition. Inflammatory bowel disease in children and adolescents: recommendations for diagnosis—-the porto criteria. JPGN 2005;41:1-7.

17. Silverberg MS, Satsangi J, Ahmad T et al. Towards an integrated clinical, molecular and serological classification of inflammatory bowel disease: Report of a working party of the 2005 montreal world congress of gastroenterology. Can J Gastroenterol 2005;19 (Suppl A): 5A-36A.

18. Levine A, Griffiths A, Markowitz J et al. Pediatric modification of the montreal classification for inflammatory bowel disease: The Paris classification. Inflamm Bowel Dis 2011;17:1314-21.

19. Thomson JM, Hansen R, Berry SH et al. Enterohepatic helicobacter in ulcerative colitis: potential pathogenic entities? PLoS ONE 2011;6:e17184.

20. Hold GL, Pryde SE, Russell VJ, Furrie E, Flint HJ. Assessment of microbial diversity in human colonic samples by $16 \mathrm{~S}$ rDNA sequence analysis. FEMS Microbiol Ecol 2002;39:33-9.

21. Dethlefsen L, Huse S, Sogin ML, Relman DA. The pervasive effects of an antibiotic on the human gut microbiota, as revealed by deep $16 \mathrm{~S}$ rRNA sequencing. PLoS Biol 2008;6:e280.

22. Ramirez-Farias C, Slezak K, Fuller Z, Duncan A, Holtrop G, Louis P. Effect of inulin on the human gut microbiota: Stimulation of bifidobacterium adolescentis and faecalibacterium prausnitzii. Br J Nutr 2009;101:533-42.

23. Bibiloni R, Mangold M, Madsen KL, Fedorak RN, Tannock GW. The bacteriology of biopsies differs between newly diagnosed, untreated, crohn's disease and ulcerative colitis patients. J Med Microbiol 2006;55:1141-9.

24. Docktor MJ, Paster BJ, Abramowicz S et al. Alterations in diversity of the oral microbiome in pediatric inflammatory bowel disease. Inflamm Bowel Dis. 2011;18:935-42.

25. Sepehri S, Kotlowski R, Bernstein CN, Krause DO. Microbial diversity of inflamed and noninflamed gut biopsy tissues in inflammatory bowel disease. Inflamm Bowel Dis 2007;13:675-83.

26. Ott SJ, Plamondon S, Hart A et al. Dynamics of the mucosa-associated flora in ulcerative colitis during remission and clinical relapse. J Clin Microbiol 2008;46:3510-3.

27. Frank DN, St Amand AL, Feldman RA, Boedeker EC, Harpaz N, Pace NR. Molecular-phylogenetic characterization of microbial community imbalances in human inflammatory bowel diseases. PNAS 2007;104:13780-5.

28. Walker AW, Sanderson JD, Churcher C et al. High-throughput clone library analysis of the mucosa-associated microbiota reveals dysbiosis and differences between inflamed and non-inflamed regions of the intestine in inflammatory bowel disease. BMC Microbiol 2011;11:7.

29. Willing B, Dicksved J, Halfvarson J et al. A pyrosequencing study in twins shows that GI microbial profiles vary with inflammatory bowel disease phenotypes. Gastroenterology 2010;139:1844-54.

30. Imielinski M, Baldassano RN, Griffiths A et al. Common variants at five new loci associated with early-onset inflammatory bowel disease. Nat Genet 2009;41:1335-40.

31. Van Limbergen J, Russell RK, Drummond HE et al. Definition of phenotypic characteristics of childhood-onset inflammatory bowel disease. Gastroenterology 2008;135:1114-22.

32. Kugathasan S, Saubermann LJ, Smith L et al. Mucosal T-cell immunoregulation varies in early and late inflammatory bowel disease. Gut 2007;56:1696-705.

33. Michail S, Durbin M, Turner D et al. Alterations in the gut microbiome of children with severe ulcerative colitis. Inflamm Bowel Dis 2012;18: 1799-808.

34. Sokol H, Pigneur B, Watterlot L et al. Faecalibacterium prausnitzii is an anti-inflammatory commensal bacterium identified by gut microbiota analysis of Crohn disease patients. PNAS 2008;105:16731-6.

35. Sokol H, Seksik P, Furet JP et al. Low counts of faecalibacterium prausnitzii in colitis microbiota. Inflamm Bowel Dis 2009;15:1183-9.

36. Medina C, Santana A, Llopis M et al. Induction of colonic transmural inflammation by Bacteroides fragilis. Implication of matrix metalloproteinases. Inflamm Bowel Dis 2005;11:99-105.

37. Mazmanian SK, Round JL, Kasper DL. A microbial symbiosis factor prevents intestinal inflammatory disease. Nature 2008;453:620-5.

38. Round JL, Mazmanian SK. Inducible Foxp3+ regulatory T-cell development by a commensal bacterium of the intestinal microbiota. PNAS 2010;107:12204-9.

39. Jia W, Whitehead RN, Griffiths $L$ et al. Is the abundance of Faecalibacterium prausnitzii relevant to Crohn's disease? FEMS Microbiol Lett 2010;310:138-44.

40. Buchanan E, Gaunt W, Cardigan T, Garrick V, McGrogan P, Russell R. The use of exclusive enteral nutrition for induction of remission in children with Crohn's disease demonstrates that disease phenotype does not influence clinical remission. Aliment Pharmacol Ther 2009;30:501-7. 
41. Otley AR, Russell RK, Day AS. Nutritional therapy for the treatment of pediatric Crohns disease. Expert Rev Clin Immunol 2010; 6:667-76.

42. Benus R, van der Werf TS, Welling GW et al. Association between faecalibacterium prausnitzii and dietary fibre in colonic fermentation in healthy human subjects. Br J Nutr 2010;104:693-700.

43. Griffiths AM. Enteral feeding in inflammatory bowel disease. Curr Opin Clin Nutr Metab Care 2006;9:314-8.

44. Khan MT, Duncan SH, Stams AJM, van Dijl JM, Flint HJ, Harmsen HJM. The gut anaerobe faecalibacterium prausnitzii uses an extracellular electron shuttle to grow at oxic-anoxic interphases. ISME J 2012;6:1578-85.

45. Huttenhower C, Gevers D, Knight R et al. Structure, function and diversity of the healthy human microbiome. Nature 2012; 486:207-14.
46. Methé BA, Nelson KE, Pop M et al. A framework for human microbiome research. Nature 2012;486:215-21.

47. Walker AW, Duncan SH, McWilliam Leitch EC, Child MW, Flint HJ. pH and peptide supply can radically alter bacterial populations and short-chain fatty acid ratios within microbial communities from the human colon. Appl Environ Microbiol 2005;71:3692-700.

48. Sghir A, Gramet G, Suau A, Rochet V, Pochart P, Dore J. Quantification of bacterial groups within human fecal flora by oligonucleotide probe hybridization. Appl Environ Microbiol 2000;66:2263-6.

(c) This work is licensed under the Creative Commons

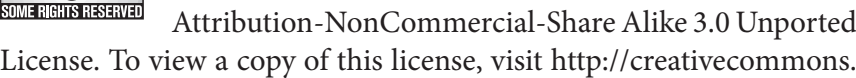
org/licenses/by-nc-sa/3.0/ 